\title{
A Research study on Relationship Between Fake News and Advertising
}

\author{
${ }^{1}$ Srija Paudel, ${ }^{2}$ Rushikesh Kamde, ${ }^{3}$ Swati Borkar, ${ }^{4}$ Dr. Priyanka Kokuntur \\ ${ }^{1,2,3}$ MBA Student (Faculty of PG), ${ }^{4}$ Faculty of Management, Department of Marketing MIT-World \\ Peace University, Pune, Maharashtra, India. ${ }^{1}$ srijapaudel3@gmail.com, \\ ${ }^{2}$ kamderushikesh54@gmail.com, ${ }^{3}$ borkarswati16@gmail.com, ${ }^{4}$ priyanka.kokuntur@mitwpu.edu.in
}

\begin{abstract}
The purpose of the paper is to study and identify the relationship between fake news and advertising. The paper provides impact of the fake news on advertising. Nowadays because of digitalization it allows publisher to provide fake information to the consumer and subsequently from consumer to each other quickly. This study also attempts the programmatic advertising where they encourage chasing of traffic between online advertisement and web sites. Fake news as a form of misinformation benefits from the fast pace that information travels in today's media ecosystem, in particular across social media platforms. An abundance of information sources online leads individuals to rely heavily on heuristics and social cues in order to determine the credibility of information and to shape their beliefs, which are in turn extremely difficult to correct or change.
\end{abstract}

KEYWORDS - Fake news brands, Programmatic Advertising, Social Media Fact Checking, Combating Fake News, Brand Management, Past Facts.

\section{INTRODUCTION}

Fake news on social media has sharply increased in the past few years. False information is not new; however, it has become a hot topic since 2017. However, the internet has enabled a whole new way to publish, share and consume information and news with very little regulation or editorial standards.

The internet and social media have made it very easy for anyone to publish content on a website, blog or social media profile and potentially reach large audiences. Many people now get news from social media sites and networks and often it can be difficult to tell whether stories are credible or not. False information can be a profitable business, generating large sums of advertising revenue for publishers who create and publish stories that go viral. The more clicks a story gets, the more money online publishers make through advertising revenue and for many publisher's social media is an ideal platform to share content and drive web traffic (Webwise, 2019) ${ }^{[9]}$.

Media can do anything to combat fake news, it has to make sure their own houses are in order, both with editorial content and advertising and especially with sponsored content and native advertising from third-party providers. In the past, you needed a lot of resources to start a rumour. It took media power and resources to start a rumour and spread it widely. But those days are gone, thanks to social media. The reach is massive, anyone can start a rumour and, if they feed it to the right channel, it spreads within minutes. To make matters worse, what we still think of as "mass media" - television, radio and newspapers - are minuscule compared to social platforms, the new mass media, where it is easy to share false and misleading posts, either by design or inadvertently (Schantin, n.d.) ${ }^{[6]}$.

A study conducted by Statista found that $42 \%$ of fake news in 2017 was generated and distributed through social media in the United States. This is significant, as a study by the Pew Research Foundation recorded that $67 \%$ of Americans get at least some of their news from social media platforms. And while fake news continues to proliferate among consumers, it is also having a substantial impact on how digital marketers buy advertising and how corporate communications professionals engage with media $\left(\right.$ SCHECHER, 2018) ${ }^{[7]}$. 


\section{LITRATURE REVIEW}

This study provides several new insights about the most effective ways to counter fake news on social media.

\section{Fake news brands:}

Most concerning for a brand is that, because online programmatic advertising has required advertisers to cede control over where their advertisements are displayed, many brands inevitably will find their advertisements on fake-news websites alongside controversial and inflammatory content. Beyond the ethical dilemma for brands is the potential loss of credibility. For established brands, things is a smaller amount dire, however, and, there could also be room for a better service option that provides advertisers tighter control over the display of their advertisements.

Digitization allows such fake news to propagate more rapidly than it ever has before, first from publishers to consumers and subsequently from consumers to each other. Scholars increasingly are paying attention to the fake-news phenomenon to define it and assess its explosion across traditional and digital channels.

\section{Programmatic advertising:}

Programmatic advertising means that ultimately the advertisements chase the traffic. It thus is financially rewarding for website owners to drive as much traffic as possible to as many pages as possible. It is highly efficient, extremely cost-effective, virtually immediate, and designed almost completely around reaching the individual target consumer. Fake news can become a threat to reputational capital and brand equity when brands are associated with and seen as financially subsidizing these types of unethical websites. Because most brands prefer to occupy relatively noncontroversial and positive positions, the more controversial the fake-news website is, the less favorably the brand's advertising on that site will be received. One of the silver linings is that our current programmaticadvertising system is both effective and incredibly efficient (West, 2019) ${ }^{[10]}$.

\section{Social Media Fact Checking:}

Over the past few years, misinformation has exploded online. Hoaxes go viral on social media after most breaking news events, manipulated videos dupe internet users into sharing them and fake news sites publish fabricated stories and cash in on the traffic. Fact-checking is most important when the user wants to believe a headline; flagging a headline when the user was unlikely to believe it without the flag adds little value. Thus, we focus on the situation where a user is inclined to believe a fake headline, but it is flagged as false (Moravec, 2019) ${ }^{[3]}$.

Researchers found that when fake news headlines were flagged with a tag that says "Rated false," people were less likely to accept the headline as accurate than when headlines carried a "Disputed" tag. They also found that posting a general warning telling readers to beware of misleading content could backfire. After seeing a general warning, study participants were less likely to believe true headlines and false ones (Ordway, 2020) ${ }^{[4]}$.

\section{Combating Fake News:}

Rumour and false stories have probably been around as long as humans have lived in groups where power matters. Until the press was invented, news was usually transferred from person to person via word of mouth. The ability to have an impact on what people know is an asset that has been prized for many centuries (Burkhardt, 2017) ${ }^{[1]}$.

Fake news spreads from sources to consumers through a complex ecosystem of websites, social media, and bots. Features that make social media engaging, including the ease of sharing and rewiring social connections, facilitate their manipulation by highly active and partisan individuals that become powerful sources of misinformation.

\section{Brand Management:}

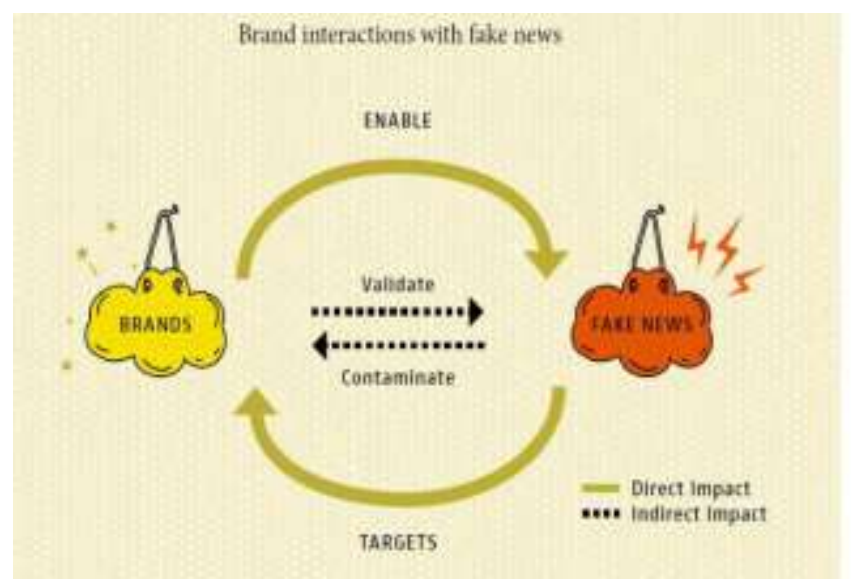

(Pierre R. Berthon, 2018) $^{[5]}$

Fig: 1 Brand interaction with fake news 
By being purveyors of truthiness brands place themselves at risk. However, the abundance of fake news and post-fact in our post-rational era are even more powerful forces imperilling brands.

We propose two kinds of solutions for both sources of risk: First, technical actions that can be undertaken to address false news and, second, systemic steps that can be undertaken to rethink the management of brands in order to inoculate against various forms of "fakery" and to reestablish stakeholder trust. (Pierre R. Berthon, 2018) ${ }^{[9]}$

The diagram describes the direct and the indirect impact on brands due to fake news. To every fake news propagated about the brands, the brand needs to clarify itself and disassociate with the respective fake news. One of the major example of it is fraudulent done in name of banks. The malicious activity is done through calling random people and ask there banking details. Thus, the cyber-crime somehow manages to broadcast various fake news to get execute such crimes.

\section{Past Facts:}

The "post-fact" world is, simply, what you wish it to be, regardless of objective, verifiable statements. Marketing and post-fact merge on mainstream and social media and can often be tied to one other. This not only spells trouble for brands, it places them at risk. One such area of trouble forbrands is fake news. Fake news is nothing new. However, in the recent past, the scale of the problem has grown exponentially. Incongruously, the information age has simultaneously given us the misinformation age. When individuals select both the stories they read and the people they interact with, opinions and views are reinforced in an echo chamber driven by positive feedback loops. The truth more and more becomes my truth. Thus, the social media Internet's truth is rather popularity and truth is my truth. These two tendencies both crave and fuel the spread of fake news. (Pierre R. Berthon, 2018) ${ }^{[9]}$

\section{OBJECTIVE OF THE STUDY}

1. To identify the relationship between fake news and advertising.

2. To study the brand management in the era of programmatic advertising.
3. To study the impact of fake news brands.

\section{RESEARCH MODELS}

In this study, the research model that was made to examine the relationship between fake news and advertising.

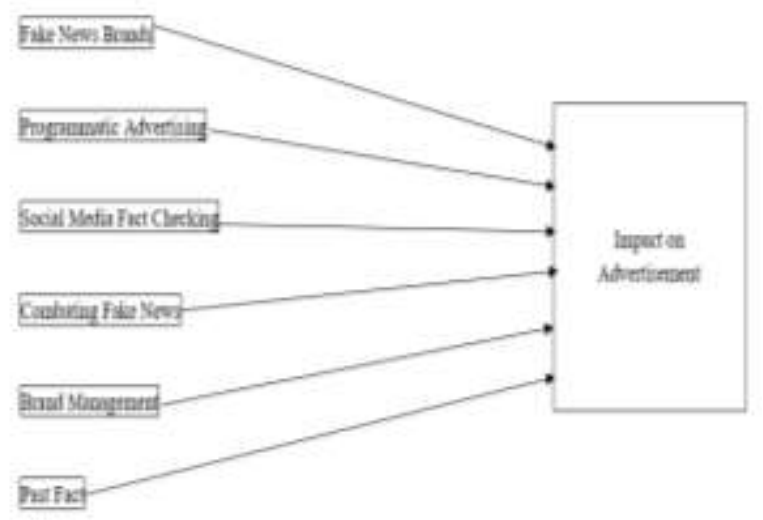

Fig: 2 Proposed research Model

Searching for a better understanding of impact on the advertising as this model has led to some interesting research. The above model helps to understand the responsible in part of the business model as well, which is based on reach and on generating traffic. Advertisements and fake news into increasing strike, which has significant implications for not only marketing, but also companies' reputations.

To assess the structural model, we evaluated the strength of relationships between variables and the predictive power of the model. The schematic diagram of the research model above shows the relationship between the dependent and independent variable.

The dependent variable is analysed in order to find out the solution to the problem. While the independent variables in the research are Fake News brands, Programmatic Advertising, Social Media Fact Checking, Combating Fake News, Brand Management, Past Facts. The independent variables are believed to be the variables that influences the dependent variable (Impact on advertisement) in either a positive or a negative way.

The main motive is to bridge the gap between the length of time it takes to produce accurate work and the acceleration of change within practice. It explains "fake news" and its complicated relationship with advertising. It also highlights 
that advertising and fake news appears to be locked in a growth cycle driven by financial incentives.

\section{HYPOTHESIS}

The following hypothesis are developed from the proposed research model.

H1: There is a significant relationship between Fake News Brands and impact on advertising.

H1a: There is no significant relationship between Fake News Brands and impact on advertising.

$\mathrm{H} 2$ : There is a significant relationship between Programmatic Advertising and impact on advertising.

H2a: There is no significant relationship between Programmatic Advertising and impact on advertising.

H3: There is a significant relationship between Social Media Fact Checking and impact on advertising.

H3a: There is no significant relationship between Social Media Fact Checking and impact on advertising.

H4: There is a significant relationship between Brand Management and impact on advertising.

H4a: There is no significant relationship between Brand Management and impact on advertising.

H5: There is a significant relationship between Past Facts and impact on advertising.

H5a: There is a significant relationship between Past Facts and impact on advertising.

\section{RESEARCH METHODOLOGY}

Secondary sources of data have been used for analysis in this research study. All relevant secondary data is collected from various sources like Internet, Books, Magazines, and Articles etc. The above structural model reveals support for all of the hypotheses presented. The paper is of descriptive nature. It is to provide answers to the questions of who, what, when, where, and how associated with the research objective. Descriptive research is used to obtain information concerning the current status of the phenomena and to describe "what exists" with respect to variables or conditions in a situation. The survey defined fake news as content that lacks sources and often users' sensational headlines to encourage the consumption and spread of unverified or false information.

In fact, 83\% of US marketers polled in November 2017 assigned the burden of solving the fake news ad problem to publishers and media companies. Social media platforms were blamed by $73 \%$ of respondents.

The survey also found that a relatively high number of marketers were divorced from their ad placements.

Some $42 \%$ said they didn't know where all of their ads were running (Chadha, 2018).

For this study, 468 consumers were shown an example of the 2016 Facebook posts, but were not told the information was false. At this point, the researchers informed the consumers that the Facebook posts were fake news, after which the study participants answered another series of survey question.

The researchers found that the more consumers felt they could detect and evaluate misinformation, the more likely they were to feel that the post was intended to manipulate readers. Similarly, the less consumers trusted Facebook, the more likely they were to feel that the post was intended to manipulate readers and they become more sceptical (Times, 2019).

\section{DATA ANLYSIS}

For the following research we have referred to secondary data. This paper provides an impact of the fake news on brand, Programmatic advertising, past facts and fact checking. This study also attempts to identify the relationship between fake news and advertising.

It can be analysed that the two factors are key to understanding the explosion of fake news: diffusion and generation. The researchers found that false-news stories diffused significantly further, faster, deeper, and more broadly than truthful new stories. This is because, overall, fake news is more novel and more affectively engaging than truthful news.

Fake news elicits high-arousal emotional responses, such as fear, disgust, and surprise, whereas truthful news stories lead to lower arousal emotional responses, such as sadness, joy, and anticipation with respect to the generation of fake news, there are three possible drivers for the creation of disinformation-Inadvertent disinformation, Ideological disinformation, Exploitative disinformation.

Taken together with the effects digitalization has had on the news industry, this has created the perfect storm for brands and advertising (West, 2019). 


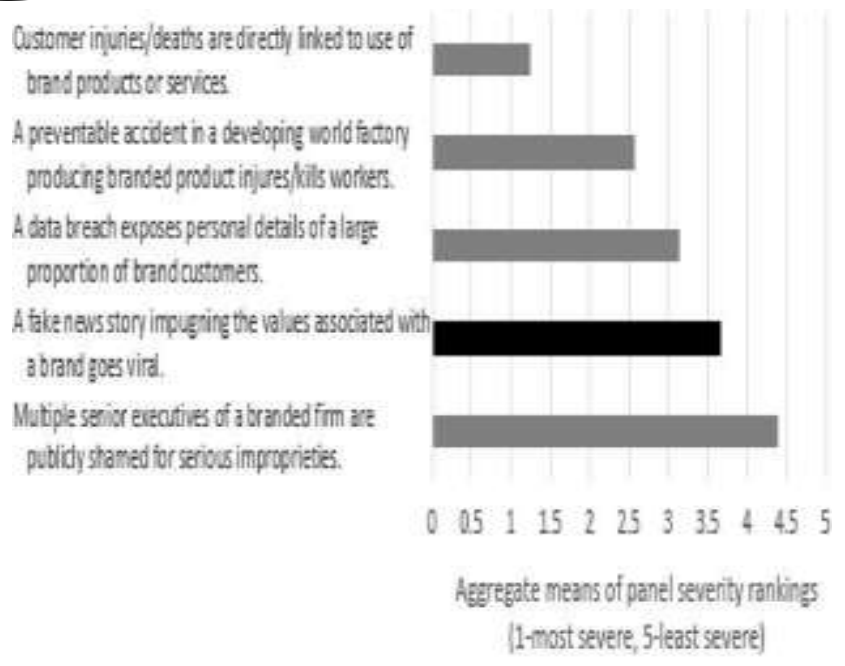

Fig: 3 Brand threat scenarios ordered by decreasing perceived severity (Andrew Flostrand, 2019) ${ }^{[11]}$

The severity of the of the problem "a fake news story impugning the values associated with a brand goes viral" is more than 3.5 which higher than any other problems. Which makes the following research study hypothesis (H1)

There is a significant relationship between Fake News Brands and impact on advertising, (H2) There is a significant relationship between Programmatic Advertising and impact on advertising \& (H4) There is a significant relationship between Brand Management and impact on advertising true.

The only problem which has severity ranking more than 4 is "Multiple senior executives of a branded firm are publicly shamed for serious improprieties". which is actually an outlier problem and does not happens to occur frequently.

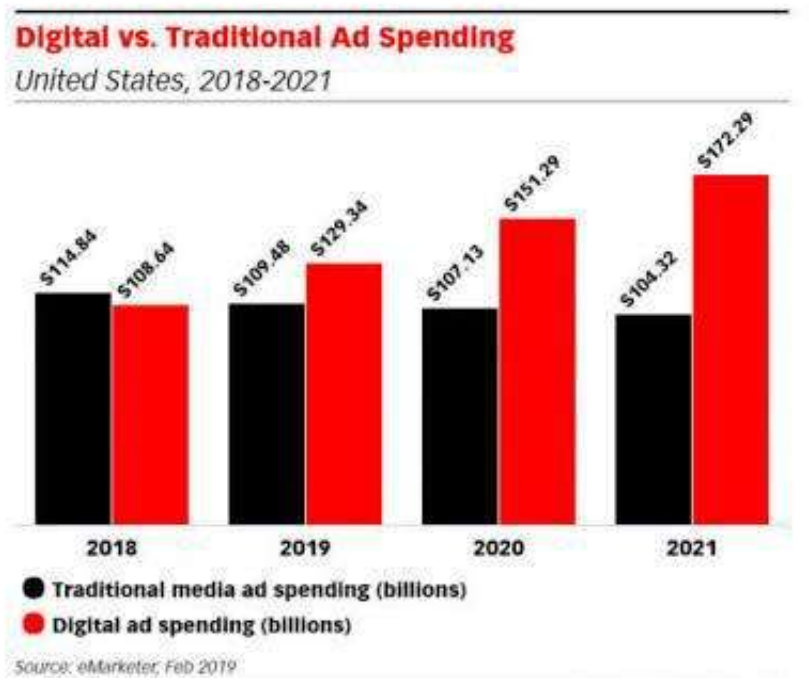

Fig: 4 Digital Vs. Traditional Ad Spending
The following research study make hypothesis (H1) There is a significant relationship between Fake News Brands and impact on advertising, (H2) There is a significant relationship between Programmatic Advertising and impact on advertising \& (H4) There is a significant relationship between Brand Management and impact on advertising true.

The bar graph represantation of the media spending which goes on increasing year by year and also forecasted to grow in a significant amount of increase in next year. This increase is not only because of internet penetration increase but and more people on social media but also to put a system against the incerease in fake news content.

\section{CONCLUSION}

The identification of fake news is a complex issue. The advertising and fake news appear to be locked in a growth cycle driven by financial incentives.

This study investigated fake news and its correct identification by users who encountered it by seeing advertisements. Scholars increasingly are paying attention to the fake-news phenomenon to define it and assess its explosion across traditional and digital channels.

We found that false-news stories diffused significantly further, faster, deeper, and more broadly than truthful new stories. Since fake news gained popularity on online platforms, this topic is currently very relevant and it is of high importance to the media and researchers to examine fake news and its impact on advertisement.

\section{FINDINGS}

Our results add to this paper that fake news is a major societal problem. Also, we have done little research on the effectiveness of the many proffered options. More research is needed to aware the people for reading the fake news. Fake news awareness is a significant predictor of perceptions of media credibility. We also found that consumers more likely will evaluate brand advertising on fake-news websites negatively and more likely will have those negative evaluations stay in memory. Finally, this study finds that trust in network, media credibility, and user intention to share are antecedents of information verification behaviour. Fake news is a present and growing 
problem in society. This research is an important first step to expand our understanding, and offers new directions for future research.

\section{FUTURE SCOPE}

The social media is a big giant which can be controlled by governments but that makes it an

obligation towards the freedom of speech. However even though in communist govern demographics like china something comes out so its very hard to tame it.

However, more fact checkers and differentiating factors from the real facts and the fake news should be distinct enough. The research study to do for it is very important.

Also, the brands should be proactive in condemning and disassociating themselves from any fake news trying to defame them or to spread any fake goodwill about them, so the analysis in them should built with help of AI and machine learning tools to defend themselves from those malicious activities.

\section{REFRENCES}

[1] Burkhardt, J. M. (2017, December). Combating Fake News in the Digital Age. (S. Imburgia, Ed.) American Library Association, 53 37. Retrieved April 2020, from https://www.journals.ala.org/index.php/ltr/issue/viewFile/662/423

[2] Chadha, R. (2018, January 3). Who's to Blame for Fake News Ads? Retrieved 2020, from eMarketer: https://www.emarketer.com/content/who-s-to-blame-for-fake-newsads

[3] Moravec, P. L. (2019, December). Fake News on Social Media. MIS Quarterly, 3, 32. Retrieved April 2020, from https://papers.ssrn.com/sol3/papers.cfm?abstract_id=3269541

[4] Ordway, D.-M. (2020, January 13). Fake news and fact-checking. Retrieved April 11, 2020, from Journalists Resource: https://journalistsresource.org/studies/society/news-media/fakenews-fact-checking-research-2019/

[5] Pierre R. Berthon, E. T. (2018). How Truthiness, Fake News and Post-Fact Endanger Brands and What to Do About It. GfK MIR, 06.

[6] Schantin, D. (n.d.). Native Advertising Institute. Retrieved April 2020, from Advertising and Fake News: https://www.nativeadvertisinginstitute.com/blog/native-advertisingand-fake-news-trust/

[7] SCHECHER, E. (2018, February 26). Turbine Labs. Retrieved April 9, 2020, from Fake News and Its Impact on Marketing and Public
Relations: https://www.turbinelabs.com/blog/fake-news-and-itsimpact-on-marketing-and-public-relations

[8] Times, T. E. (2019, Octorbur 18). Brands are resilient against 'fake news' on social media. Retrieved April 2020, from Brand Equity: https://brandequity.economictimes.indiatimes.com/news/digital/bran ds-are-resilient-against-fake-news-on-social-media/71650191

[9] Webwise. (2019). European Union's Connecting Europe Facility. Retrieved April 11, 2020, from Webwise: https://www.webwise.ie/teachers/what-is-fake-news/

[10] West, D. C. (2019). The relationship between fake news and advertising. Journal of advertising research, 3-8.

[11] Andrew Flostrand, L. P. (2019). Fake news and brand management: a Delphi study of impact, vulnerability and mitigation. Product \& Brand Management, 09.

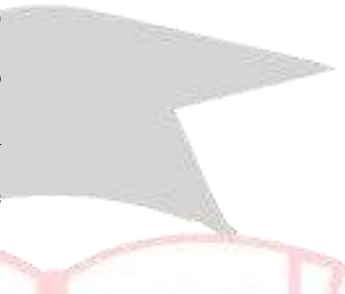
m

\section{年}

